\title{
Uncertainty Based Operating Strategy Selection in Combined Heat and Power Systems
}

\author{
William C. Long, Rogelio Luck, Pedro J. Mago ${ }^{1}$ \\ Mississippi State University, Department of Mechanical Engineering, Mississippi State, MS, \\ USA
}

\begin{abstract}
Combined heat and power (CHP) research has focused on optimizing the operation of CHP systems based on various criteria, such as cost savings, energy usage, or emissions. In literature, different operating strategies, such as base loading (BL), following electric load (FEL), and following thermal load (FTL), of a CHP system are typically compared and the best operation strategy selected based on the desired optimized parameter. To date, a literature survey indicates that the uncertainties associated with these calculations have not been considered in the operating strategy selection process. Therefore, this study considers the uncertainties in the cost savings associated with operating the CHP system under BL, FEL, and FTL operating strategies. Modular uncertainty analysis techniques are used to compare the uncertainties associated with the cost savings of the different operating modes. Results indicate that, due to overlapping uncertainty bands, the choice between different CHP operating strategies cannot always be clearly determined for power generation units with nominal sizes less than approximately $60 \%$ of the building's maximum electric load. In such cases, the choice between CHP operating strategies may be decided based on ease of implementation and operation.

Keywords: Modular uncertainty analysis, Combined Heat and Power, Base Loading, Following Electrical Load, Following Thermal Load
\end{abstract}

\section{Nomenclature}

$\alpha$ - Fraction of maximum electrical requirement of building

$a$ - First constant of PGU relationship in Eq. (4)

$b$ - Second constant of PGU relationship in Eq. (4)

$\eta_{b o i l e r}$ - Boiler efficiency

$\eta_{h c}$ - Heating coil efficiency

\footnotetext{
${ }^{1}$ Corresponding author, Email: mago@me.msstate.edu
} 
$\eta_{\max }$ - Maximum efficiency of PGU

$\eta_{p g u}-\mathrm{PGU}$ efficiency

$\eta_{\text {rec }}$ - Heat recovery system efficiency

Cost $_{B L}$ - BL mode hourly operating cost

$\operatorname{Cost}_{\text {conv }}$ - Conventional mode hourly operating cost

Cost $_{\text {conv-BL }}$ - Hourly operating cost reduction of BL from conventional operating mode

Cost $t_{c o n v-F E L}$ - Hourly operating cost reduction of FEL from conventional operating mode

$\operatorname{Cost}_{\text {conv-FTL }}$ - Hourly operating cost reduction of FTL from conventional operating mode

Cost $_{\text {FEL }}$ - FEL mode hourly operating cost

Cost $_{\text {FTL }}$ - FTL mode hourly operating cost

$C_{e}$ - Rate cost of electricity

$C_{f}$ - Rate cost of natural gas

$E_{b}$ - Building's electrical requirement

$E_{\text {grid }}$ - Electricity purchased from the grid

$E_{p g u}$ - Electrical output of PGU

$E_{\text {nom }}$ - Nominal size of PGU

$F_{b}$ - Building's natural gas requirement when operating in a conventional mode

$F_{\text {boiler }}$ - Natural gas requirement of boiler

$F_{m}$ - Natural gas as measured at the meter

$F_{p g u}$ - Natural gas requirement of PGU

$M_{B L}$ - BL mode monthly operating cost

$M_{\text {conv }}$ - Conventional mode monthly operating cost

$M_{c o n v-B L}$ - Monthly operating cost reduction of BL from conventional operating mode

$M o n_{\text {conv-FEL }}$ - Monthly operating cost reduction of FEL from conventional operating mode

$M_{\text {conv-FTL }}$ - Monthly operating cost reduction of FTL from conventional operating mode

$M o n_{F E L}$ - FEL mode monthly operating cost 
$M_{\text {FTL }}$ - FTL mode monthly operating cost

$Q_{b}$ - Building's heat requirement

$Q_{\text {boiler }}$ - Boiler heat produced

$Q_{h c}$ - Building's heating coil requirement

$Q_{\max }$ - Maximum recoverable heat output of PGU

$Q_{r}$ - Recoverable heat from PGU

Year $_{B L}$ - BL mode yearly operating cost

$Y_{\text {earv }}$ - Conventional mode yearly operating cost

Year $r_{\text {conv-BL }}$ - Yearly operating cost reduction of BL from conventional operating mode

Year $_{\text {conv-FTL }}$ - Yearly operating cost reduction of FTL from conventional operating mode

Year $_{c o n v-F E L}$ - Yearly operating cost reduction of FEL from conventional operating mode

Year $_{F E L}$ - FEL mode yearly operating cost

Year $_{F T L}$ - FTL mode yearly operating cost

\section{Introduction}

A building's heating and electrical needs are often met by purchasing fuel and purchasing electricity from the grid. A combined heat and power (CHP) system helps meet a building's heating and electrical needs by way of a power generation unit (PGU). PGU in a CHP system produces electricity that partially or completely offsets the amount of electricity that must be purchased from the grid to satisfy the building electric load. The heat generated by the PGU is used to partially or completely offset the amount of heat that must be supplied by the conventional heating system of the building. There are several operating strategies that can be used to control the operation of a CHP system. The most common operating strategies are base loading (BL), following the electrical load (FEL), and following the thermal load (FTL). The BL operating mode, as discussed by Smith et al. [1], consists of operating the PGU at a constant base load such that the PGU always produces a constant amount of heat and electricity that is used to offset the building's heating and electrical requirement. Any excess electricity that might be produced from a CHP operating under BL can be sold back to the grid to reduce the operating cost of the CHP system. However, selling excess electricity that is produced by the CHP system is not always an option available in every geographical location. The FEL operating mode 
consists in running the PGU such that it meets the building's electrical requirement. The heat that is produced by the PGU while operating under FEL is used to offset the building's heating requirement. On the other hand, the FTL operating mode consists of operating the PGU such that the heat generated by the PGU follows the instantaneous building's heating requirement. The electricity that is produced while operating under FTL is used to offset the building's electrical requirement. Just as in the case of the BL mode, any excess electricity that is produced when using a FTL mode may be sold back to the grid, if possible.

The performance of CHP systems have been a popular topic of research, as can be seen in the works of Jannelli et al. [2], Kong et al. [3], Li et al. [4], Skorek-Osikowska et al. [5], Sun et al. [6], Toja-Silva and Rovira [7], Thorin et al. [8], Sonar et al. [9]. Sonar et al. [9] conducted a review of micro-trigeneration CHP systems. [9] discusses the added benefits of CHP systems such as energy security, reducing environmental threats, and sustainability. Jannelli et al. [2] evaluated a small-sized combined cooling, heat, and power (CCHP) system using simulation techniques. They showed that the proposed CCHP system was rated on three system performance criteria: energy utilization factor (EUF), exergy utilization factor (ExUF), and trigeneration primary energy saving (TPES). The best performance was found when the cooling power demand was low. Kong et al. [3] experimentally investigated a micro-CCHP system driven by a gas engine. They found that the proposed system had combined thermal and electrical efficiencies over 70\%. Li et al. [4] studied the utilization of energy sources for CCHP systems, and the fuel energy saving ratio (FESR) was compared for many configurations and sizes of CHP systems. Skorek-Osikowska et al. [5] investigated the effectiveness of using biomass gasification in CHP systems. They found that the economic viability depends on many factors. The price of green certificates and the price of fuel are factors that showed the most influence. They found that green certificate prices must be greater than $26.75 € / \mathrm{MWh}$ and fuel prices lower than $9.62 € / \mathrm{GJ}$ in order for CHP systems utilizing biomass gasification become economically feasible. Sun et al. [6] analyzed a CHP system consisting of an ejector heat exchangers and absorption heat pumps. They found that implementing such components decreased the amount of steam extracted from a steam turbine by $41.4 \%$ and increased the heat transmission capacity of the existing primary heating network by $66.7 \%$. Toja-Silva and Rovira [7] studied the use of hydrogen-fueled microgas turbine for use in a CHP system. Their analysis showed that use of such a turbine resulted in an energy efficiency of $89.4 \%$ and an exergy 
efficiency of 45.7\%. Thorin et al. [8] developed a method for long-term optimization of a CHP system using linear-programming and Lagrangian relaxation to maximize profit.

The CHP operating strategy selection has also been the point of focus by many researchers including Alipour et al. [10], Cardona and Piacentino [11], Fumo et al. [12, 13], Jalalzadeh-Azar [14], Kang et al. [15], Knizley et al. [16], Mago et al. [17, 18, 19], Smith and Mago [20], Smith et al. [1], Sun et al. [21], Wang et al. [22], Wu and Wang [23]. Cardona and Piacentino [11] conducted analyses of a pilot plant implementing a CHP system in different operating strategies. They found that implementing any type of operating mode for the CHP system would produce annual savings for their plant. Fumo et al. [13] studied the effects that CHP systems have on the primary energy consumption (PEC). They found that the CHP system studied increased the site energy consumption (SEC). Kang et al. [15] compared a CHP system to a combined cycle system using a $5 \mathrm{MW}$-class gas turbine fueled with biogas. The CHP system of their study showed higher economic benefits when compared to the combined cycle they studied. Wang et al. [22] conducted a study of a CHP system operating under FEL and FTL strategies in a simulated building in Beijing, China. They found that the FEL operating mode produces more benefits in the Winter than in the Summer when energy consumption and emissions were of concern. Mago et al. [17] conducted analyses of a CHP system implementing different operating strategies where operating cost and PGU emissions were studied. The study found that the only operating mode that reduced the operating cost and emissions was the FTL mode for all the locations studied; Boston, MA, San Francisco, CA, Columbus, MS, and Miami, FL. It was also found that the FEL mode reduced the operating cost for the city of San Francisco, CA. Mago et al. [19] conducted a study of a CHP system that takes advantage of using two PGUs implementing FEL and FTL. They compared a dual CHP (DCHP) system against a typical CHP system with one PGU implementing BL, FEL, and FTL strategies. Their study found that, for Atlanta, GA and San Francisco, CA, all operating strategies studied reduced operating cost and emissions. For the city of Duluth, MN, the study finds that a DCHP system implementing a FTL operating mode is the only operating mode that reduces both operating cost and emissions. For the city of Phoenix, AZ, the study finds that a CHP system operating a single PGU in a FTL operating mode is the only configuration that presents a operating cost reduction. They found the FEL mode applied to either a CHP or DCHP system was the only operating mode to reduce emissions. Jalalzadeh-Azar [14] investigated the overall system efficiency of a CHP system 
implementing both FEL and FTL on a monthly basis. He found that for the months of March through October, the overall system efficiency of the CHP system rises for both operating strategies. The highest overall system efficiency was found in the month of July and the lowest overall system efficiency in the month of November for both operating strategies. Smith and Mago [20] studied a CHP system implementing FEL and FTL along with a hybrid method. The hybrid method used either a FEL or FTL operating mode depending on the electrical and heating requirements of the building to minimize any excess electricity or heat that would have been generated by a CHP system implementing solely a FEL or FTL operating mode. They found that the hybrid method is more efficient than operating solely by FEL or FTL.

To date, a literature survey indicates that the uncertainties associated with a cost reduction analysis have not been considered in the operating strategy selection process. Therefore, the objective of this paper is to investigate the uncertainties associated with the cost savings that could be obtained for the different operating strategies including BL, FEL, and FTL. To achieve this, modular uncertainty analysis techniques are used to compare the uncertainties associated with the cost savings of the different operating strategies evaluated in this paper.

\section{Analytical Methods}

\subsection{CHP Model}

The CHP model presented in this section is adapted from Mago et al. [18]. The building and associated components consist of a typical Chicago, Illinois restaurant, a boiler, a power generation unit (PGU), a heat recovery system, and a heating coil. A schematic of the building and associated components can be found in Figure 1. The building description can be found in Table 1. The electric and heat requirement of the building are generated by using EnergyPlus software [30]. EnergyPlus is a software package produced by the United States Department of Energy that simulates a building's energy usage based upon user input building parameters and historical weather data. The restaurant building used in this paper is part of the U.S. Department of Energy (DOE) commercial reference building data set [30] that may be found on the U.S. DOE website. The building's fuel usage, $\dot{F}_{b}$, can be found by

$$
\dot{F}_{b}=\frac{\dot{Q}_{b}}{\eta_{b o i l e r} \eta_{h c}}
$$

The building's heating requirement, $\dot{Q}_{b}$, is supplied by the building's heating coil. The heating 
coil heat requirement, $\dot{Q}_{h c}$, is

$$
\dot{Q}_{h c}=\frac{\dot{Q}_{b}}{\eta_{h c}}
$$

The nominal PGU size, $\dot{E}_{n o m}$, is expressed as a fraction of the building's maximum electrical load as follows.

$$
\dot{E}_{\text {nom }}=\alpha \max \left(\dot{E}_{b}\right)
$$

The electric output of a natural gas PGU, $\dot{E}_{p g u}$, can be expressed as a function of the fuel requirement of the PGU, $\dot{F}_{p g u}$, following a straight line, relationship

$$
\dot{F}_{p g u}=a \dot{E}_{p g u}+b
$$

where $a$ and $b$ are engine-dependent constants that are determined from curve fitting of manufacturer's data of fuel usage versus engine output. The values of $a$ and $b$ used in the paper are presented in Table 2. Cho et al. [24] and Yun et al. [25] use this relationship to relate power output to fuel consumption of the PGU. The PGU is selected such that the efficiency at the nominal PGU size, $\eta_{\max }$, is

$$
\eta_{\max }=\frac{\dot{E}_{\text {nom }}}{\dot{F}_{\max }}
$$

The heat recovered from the PGU at the nominal PGU size, $\dot{Q}_{\max }$, is

$$
\dot{Q}_{\max }=\eta_{\text {rec }}\left(1-\eta_{\max }\right) \dot{F}_{\max }
$$

\subsubsection{Conventional Operating Mode}

In the conventional operating mode, no PGU is used. All the electricity required must be purchased from the grid. The hourly operating cost of the building is then

$$
\text { Cost }_{\text {conv }}=C_{e} \dot{E}_{b}+C_{f} \dot{F}_{b}
$$

where $C_{e}$ is the unit cost of electricity, $\dot{E}_{b}$ is the building's electric load, $C_{f}$ is the unit cost of fuel, and $\dot{F}_{b}$ is building's fuel load. The monthly operating cost of the building is

$$
\operatorname{Mon}_{\text {conv }}=\sum^{m} \operatorname{Cost}_{\text {conv }}
$$

where $m$ is the number of hours. The yearly operating cost of the building is

$$
\text { Year }_{\text {conv }}=\sum \text { Mon }_{\text {conv }}
$$




\subsubsection{Base Loading}

In the base loading (BL) operating mode, a PGU runs at a constant power level, a.k.a., a base load. The electricity that the PGU produces is used to either offset the amount that is needed to be purchased from the grid or completely satisfy the building's electrical requirements. Any excess electricity that is produced can, in certain instances, be sold back to the grid. The waste heat from the PGU is used to offset the amount of heat needed from the boiler or completely satisfy the building's heat requirements. The heat required of the boiler is

$$
\dot{Q}_{\text {boiler }}=\left\{\begin{array}{cc}
\text { if } \dot{Q}_{h c}>\dot{Q}_{\text {max }}, & \dot{Q}_{h c}-\dot{Q}_{\text {max }} \\
\text { else }, & 0
\end{array}\right.
$$

The fuel required of the boiler is

$$
\dot{F}_{\text {boiler }}=\frac{\dot{Q}_{\text {boiler }}}{\eta_{\text {boiler }}}
$$

The net fuel requirement of the building is

$$
\dot{F}_{m}=\dot{F}_{\text {max }}+\dot{F}_{\text {boiler }}
$$

The electricity to be purchase from the grid is

$$
\dot{E}_{\text {grid }}=\left\{\begin{array}{cc}
\text { if } \dot{E}_{b}>\dot{E}_{\text {nom }}, & \dot{E}_{b}-\dot{E}_{\text {nom }} \\
\text { else, }, & 0
\end{array}\right.
$$

The hourly operating cost of the building is

$$
\operatorname{Cost}_{B L}=C_{e} \dot{E}_{g r i d}+C_{f} \dot{F}_{m}
$$

\subsubsection{Following Electric Load}

In the Following Electric Load (FEL) operating mode, a PGU is run such that it matches the electric requirement of the building. The waste heat from the PGU is used to offset the amount of heat needed from the boiler or completely satisfy the building's heat requirements. The electricity produced by the building's PGU is set by the building's electric requirement or by the nominal PGU size. This is shown below.

$$
\dot{E}_{p g u}=\left\{\begin{array}{cc}
\text { if } \dot{E}_{b}>\dot{E}_{n o m}, & \dot{E}_{n o m} \\
\text { else, } & \dot{E}_{b}
\end{array}\right.
$$

The conditional aspect of the relationship arises from the limit of what the PGU is able to provide. If the building's electric requirement is greater than that of the PGU size, the PGU operates at maximum electrical output. If the building's electric requirement is less than that of 
the PGU size, the PGU matches the building's electric requirement. The PGU efficiency is

$$
\eta_{p g u}=\frac{\dot{E}_{p g u}}{\dot{F}_{p g u}}
$$

The heat recovered from the PGU is

$$
\dot{Q}_{r}=\eta_{r e c}\left(1-\eta_{p g u}\right) \dot{F}_{p g u}
$$

The heat requirement of the boiler is

$$
\dot{Q}_{b o i l e r}=\left\{\begin{array}{cc}
\text { if } \dot{Q}_{h c}>\dot{Q}_{r}, & \dot{Q}_{h c}-\dot{Q}_{r} \\
\text { else }, & 0
\end{array}\right.
$$

The fuel requirement of the whole building is

$$
\dot{F}_{m}=\dot{F}_{p g u}+\dot{F}_{b o i l e r}
$$

The electricity to be purchase from the grid is

$$
\dot{E}_{\text {grid }}=\left\{\begin{array}{cc}
\text { if } \dot{E}_{b}>\dot{E}_{p g u}, & \dot{E}_{b}-\dot{E}_{p g u} \\
\text { else }, & 0
\end{array}\right.
$$

The hourly operating cost of the building is

$$
\operatorname{Cost}_{F E L}=C_{e} \dot{E}_{g r i d}+C_{f} \dot{F}_{m}
$$

\subsubsection{Following Thermal Load}

In the following thermal load (FTL) operating mode, a PGU is run such that it matches the heat requirement of the building. The electricity that the PGU produces is used to either offset the amount that is needed to be purchased from the grid or completely satisfy the building's electrical requirements. The heat recovered from the PGU is

$$
\dot{Q}_{r}=\left\{\begin{array}{cc}
\text { if } \dot{Q}_{h c}>\dot{Q}_{m a x}, & \dot{Q}_{\max } \\
\text { else } \frac{\dot{Q}_{r}}{\eta_{\text {rec }}}>b \dot{E}_{\text {nom }}, & \dot{Q}_{h c}
\end{array}\right.
$$

The conditional aspect of the relationship arises from the limit of what the PGU is able to provide. If the building's heating requirement is greater than that of the maximum amount of heat that the PGU is able to provide, the PGU operates at its maximum state. If the building's heating requirement is less than that of the maximum amount of heat that the PGU is able to provide, the PGU operates at a state which provides the same amount of heat that the building requires. The electricity produced by the PGU is 


$$
\dot{E}_{p g u}=\frac{\frac{\dot{Q}_{r}}{\eta_{r e c}}-b \dot{E}_{n o m}}{a-1}
$$

This relationship is derived from the works of Cho [26]. The hourly operating cost of the building is

$$
\operatorname{Cost}_{F T L}=C_{e} \dot{E}_{g r i d}+C_{f} \dot{F}_{m}
$$

The monthly operating cost of the building is

$$
M o n_{O P}=\sum^{m} \operatorname{Cost}_{O P}
$$

where $O P$ is either the BL, FEL, or FTL operating mode. The yearly operating cost of the building is

$$
\text { Year }_{O P}=\sum \text { Mon }_{O P}
$$

The hourly reduced operating cost of the building from the conventional operating mode is

$$
\operatorname{Cost}_{\text {conv }-O P}=\operatorname{Cost}_{\text {conv }}-\operatorname{Cost}_{O P}
$$

The monthly reduced operating cost of the building from the conventional operating mode is

$$
\operatorname{Mon}_{\text {conv } O P}=\sum^{m} \operatorname{Cost}_{\text {conv } O P}
$$

The yearly reduced operating cost of the building from the conventional operating mode is

$$
\text { Year }_{\text {conv-OP }}=\sum M \text { Mon }_{\text {conv } O P}
$$

\subsection{Modular Uncertainty Analysis}

Modular uncertainty analysis is an uncertainty analysis method in which linear algebra techniques are utilized. The modular method provides an efficient and convenient way of calculating uncertainties of complex systems that avoids tedious and laborious steps found in traditional uncertainty analysis methods. The modular uncertainty analysis is adapted from the works of Weathers et al. [27]. For the modular uncertainty analysis, external inputs are denoted by $N$, system components by $G$, and system component outputs by $C$. A block diagramused for the CHP operating strategy is shown in Figure 2. An arbitrary system component can be a function of both external inputs and system component outputs, as follows,

$$
C_{i}=G_{i}(N, C)
$$

Taking a Taylor series expansion about the nominal values of the external inputs, and of the system components, the outputs for an arbitrary system component can be calculated as follows 


$$
\begin{array}{r}
\Delta C_{i}= \\
\frac{\partial G_{i}}{\partial N_{1}} \Delta N_{1}+\frac{\partial G_{i}}{\partial N_{2}} \Delta N_{2}+\cdots+\frac{\partial G_{i}}{\partial N_{n}} \Delta N_{n} \\
+\frac{\partial G_{i}}{\partial C_{1}} \Delta C_{1}+\frac{\partial G_{i}}{\partial C_{2}} \Delta C_{2}+\cdots+\frac{\partial G_{i}}{\partial C_{c}} \Delta C_{c}+\text { H.O.T. }
\end{array}
$$

where $n$ is the number of external inputs, $c$ is the number of system component outputs or internal inputs, and H.O.T. are the higher order terms of the Taylor series expansion. The H.O.T. are not considered in further calculations being that they are negligible. All the system components can then be arranged in matrix form as

$$
\left(\begin{array}{c}
\Delta C_{1} \\
\Delta C_{2} \\
\vdots \\
\Delta C_{c}
\end{array}\right)=\left(\begin{array}{cccccccc}
\frac{\partial G_{1}}{\partial N_{1}} & \frac{\partial G_{1}}{\partial N_{2}} & \cdots & \frac{\partial G_{1}}{\partial N_{n}} & \frac{\partial G_{1}}{\partial C_{1}} & \frac{\partial G_{1}}{\partial C_{2}} & \cdots & \frac{\partial G_{1}}{\partial C_{c}} \\
\frac{\partial G_{2}}{\partial N_{1}} & \frac{\partial G_{2}}{\partial N_{2}} & \cdots & \frac{\partial G_{2}}{\partial N_{n}} & \frac{\partial G_{2}}{\partial C_{1}} & \frac{\partial G_{2}}{\partial C_{2}} & \cdots & \frac{\partial G_{2}}{\partial C_{c}} \\
\vdots & \vdots & \ddots & \vdots & \vdots & \vdots & \ddots & \vdots \\
\frac{\partial G_{c}}{\partial N_{1}} & \frac{\partial G_{c}}{\partial N_{2}} & \cdots & \frac{\partial G_{c}}{\partial N_{n}} & \frac{\partial G_{c}}{\partial C_{1}} & \frac{\partial G_{c}}{\partial C_{2}} & \cdots & \frac{\partial G_{c}}{\partial C_{c}}
\end{array}\right)\left(\begin{array}{c}
\Delta N_{2} \\
\vdots \\
\Delta C_{1} \\
\Delta C_{2} \\
\Delta C_{c}
\end{array}\right)
$$

This matrix form can be expressed as

$$
\Delta C=\left(\begin{array}{cc}
\nabla G & \nabla G \\
N & C
\end{array}\right)\left(\begin{array}{l}
\Delta N \\
\Delta C
\end{array}\right)
$$

where $\underset{N}{\nabla G}$ is the partial derivatives of the system components with respect to the external inputs, and $\nabla_{C}$ is the partial derivatives of the system components with respect to the system component outputs. Solving Eq. (33) for the outputs, $\Delta C$, results in

$$
\Delta C=\left(I-\nabla_{C}\right)^{-1} \nabla_{N} G \cdot \Delta N
$$

where $I$ is the identity matrix. If the terms involving the partial derivatives are denoted by $J$ as

$$
J=(I-\nabla G)^{-1} \nabla G
$$

Eq. (34) can then be written as

$$
\Delta C=J \cdot \Delta N
$$

The matrix $J$ can be seen as the Jacobian of the system components with respect to solely the external inputs. At this time, correlations should be considered. If correlations between external inputs existed, a diagonal matrix consisting of the random uncertainties of the external inputs 
would be assembled [27]. A column vector for each correlation consisting of the correlation value would be appended to this matrix to account for the correlations between external inputs. This non-square matrix would then be multiplied by the transpose of itself to form $N_{r}$. The complete process of assembling the correlation matrix and random uncertainty matrix can be found in Weathers et al. [27]. However, for this analysis none of the system inputs are correlated so the random uncertainties of the external inputs, $N_{r}$, can be arranged in matrix form as

$$
N_{r}=\left(\begin{array}{cccc}
r_{1}^{2} & 0 & \cdots & 0 \\
0 & r_{2}^{2} & \cdots & 0 \\
\vdots & \vdots & \ddots & \vdots \\
0 & 0 & \cdots & r_{n}^{2}
\end{array}\right)
$$

where $r_{i}$ is the random uncertainty associated with the $i$-th external input. The assumption that there are no correlations is made to provide a simplified model that can be built upon for future research. Similarly, the systematic uncertainties of the external inputs, $N_{s}$, can be arranged in matrix form as

$$
N_{s}=\left(\begin{array}{cccc}
s_{1}^{2} & 0 & \cdots & 0 \\
0 & s_{2}^{2} & \cdots & 0 \\
\vdots & \vdots & \ddots & \vdots \\
0 & 0 & \cdots & s_{n}^{2}
\end{array}\right)
$$

where $s_{i}$ is the systematic uncertainty associated with the $i$-th external input. As seen in Weathers et al. [27], the total uncertainties of the external inputs, $N_{u}$, can then be calculated as

$$
N_{u}=N_{r}+N_{s}
$$

The total uncertainty matrix for the system component outputs can then be found by

$$
C_{u}=J N_{u} J^{T}
$$

where the diagonal terms of the $C_{u}$ matrix are the squares of the total uncertainties of the system components.

Block diagrams for the conventional, BL, FEL, and FTL operating strategies are shown in Figure $3,4,5$, and 6, respectively. External inputs are denoted by circles and system components are denoted by rectangles. Table 3 summarizes the system components for the different operating strategies investigated in this study.

The external inputs for the different operating strategies consist of the building's electrical and natural gas requirements and the inputs given in Table 2. The uncertainties of all the heat exchangers' efficiencies are taken to be 5\% for the simulations in this study. This percentage is 
in line with values observed in the literature. For instance, a likely source of uncertainty in the heat exchanger components of the CHP system is fouling. Jeronimo et al. [28] studied the effects that fouling has on heat exchangers efficiency. For the three heat exchangers they studied, the predicted fouled heat exchanger was within $3.7 \%, 7.4 \%$, and $12.2 \%$ of the clean heat exchanger efficiency. The price of electricity and natural gas is highly dependent on the state of the market. The U.S. Bureau of Labor Statistics [29] provides monthly prices of U.S. city average for electricity and natural gas. The monthly prices of electricity and natural gas did not fluctuate greater than $3.7 \%$ and $2.9 \%$, respectively, of the average for all months in 2013. These percentages appear to be reasonable levels of uncertainties and were used for the electricity and natural gas prices. The PGU relationship coefficients were studied to understand the variation between PGUs of four different manufacturers (Cummins, GE, Generac, and Elliott MagneTek). The PGUs studied were all of equal nominal size of $30 \mathrm{~kW}$ and operated using natural gas. The PGU relationship coefficients were calculated using manufacturer's data provided for these units. The PGU relationship coefficients of four different PGUs were compared and it was found that the first and second coefficients did not fluctuate greater than $2.32 \%$ and $4.88 \%$, respectively. In light of this information, these percentages were taken as the percent uncertainty for the PGU relationship coefficients. The random and system uncertainties of all other external inputs were selected to be $5 \%$ of the nominal value of the input.

\section{Results and Discussion}

In this section, the results from the modular uncertainty analysis of the building are presented. Table 1 shows the information provided to EnergyPlus to simulate the Chicago restaurant building. Table 2 shows the nominal values, random uncertainties, and systematic uncertainties of the different components of the building and CHP system. The PGU used in the model is a natural gas engine. The random and systematic uncertainties of the external inputs are taken to be five percent of their corresponding nominal values.

Figure 7 shows the yearly operating cost reduction for each of the CHP operating strategies and a selection of PGU nominal sizes. The maximum electrical requirement of the building is $68.68 \mathrm{kWh}$. The optimal PGU size for the BL operating mode was found to be $24 \mathrm{kWh}$ and occurs at $35 \%$ of the maximum electrical requirement of the building during the year. The uncertainty associated with the cost reduction under BL operation with this optimal PGU size is approximately 23\%. The optimal PGU size for the FEL and FTL operating strategies is $34.3 \mathrm{kWh}$ 
and occurs at $50 \%$ of the maximum electrical requirement of the building. The uncertainties associated with the cost reduction for the FEL and FTL operating mode with this optimal PGU size are approximately $23 \%$ and $17 \%$, respectively. For PGU sizes of up to $60 \%$ of the building's maximum load, the uncertainty bands associated with the yearly cost reduction overlap. The overlapping uncertainty bands show that no operating mode can be selected as better than any other operating mode in this range of PGU sizes. For PGU sizes larger than 60\%, Figure 7 shows that the uncertainty bands associated with the yearly cost reduction for the BL operating mode do not overlap with the FEL and FTL operating strategies. The non-overlapping uncertainty bands in this region indicate that the yearly cost reduction for the BL operating mode will not exceed that of the FEL and FTL operating strategies. The uncertainty bands and the yearly cost reduction value for the BL operating mode in this range clearly show that the BL operating mode should not be chosen.

Figure 8 shows the monthly operating cost of the four different operating strategies with a PGU nominal size of $35 \%$ of the maximum electrical load of the building. The PGU size was chosen because it was found to be the optimal PGU size when performing in a BL operating mode. The monthly operating cost of the conventional, BL, FEL, and FTL operating strategies range from \$2969-\$4955, \$2607-\$4409, \$2525-\$4324, and \$2471-\$4262, respectively. The minimum operating cost for all operating strategies occur during the month of September. The uncertainties corresponding to the operating cost of the conventional, BL, FEL, and FTL operating strategies for the month of September are $\$ 185, \$ 88, \$ 91$, and $\$ 74$, respectively. The maximum operating cost for all operating strategies occur during the month of January. The uncertainties corresponding to the operating cost of the conventional, BL, FEL, and FTL operating strategies for the month of January are $\$ 393, \$ 286, \$ 290$, and $\$ 292$, respectively. From figure 8 , the uncertainty bands for all operating strategies overlap with the conventional uncertainty band for the months of January and December. The overlapping uncertainty bands during these months indicate that implementing a CHP system amy not reduce operating costs, and hence implementing a CHP system may not always reduce operating cost. During the months of April through November, the uncertainty bands of the CHP operating strategies do not overlap with the conventional uncertainty bands. For these months, the use of CHP system under any operating mode would produce cost savings. In addition to these months, figure 8 shows that both, the FEL and FTL operating strategies for the months of February, and March would 
produce a cost savings.

Figure 9 shows the yearly operating cost reduction of the operating strategies with a variety of PGU nominal sizes based upon monthly electrical and natural gas requirement. The maximum monthly electrical requirement of the building is $40.6 \mathrm{kWh}$. The optimal PGU size for BL, FEL, and FTL operating strategies is $32.5 \mathrm{kWh}$ and occurs at $80 \%$ of the maximum electrical requirement of the building, and the corresponding uncertainties associated with the cost reduction are approximately 19\%,19\%, and 18\%, respectively. The uncertainty bands for all operating strategies overlap for the entire range of PGU sizes. The FEL operating mode can then be chosen due to it's ease of implementation and operation.

Figure 10 shows the monthly operating cost of the four different operating strategies with a PGU nominal size of $80 \%$ of the maximum monthly electrical requirement of the building. The monthly operating cost of the conventional, BL, FEL, and FTL operating strategies range from $\$ 2969-\$ 4955, \$ 2445-\$ 3819, \$ 2445-\$ 3819$, and $\$ 2455-\$ 3819$, respectively. The minimum operating cost for all operating strategies occurs in April. The uncertainties associated with the operating cost of the conventional, BL, FEL, and FTL operating strategies for April are $\$ 252, \$ 168, \$ 170$, and $\$ 181$, respectively. The maximum operating cost for all operating strategies occurs in January and the uncertainties for this month are $\$ 409$ for the conventional operating mode and $\$ 396$ for the other operating strategies. For the months of October through May, the uncertainty bands for the BL, FEL, and FTL operating mode do not overlap with the conventional uncertainty band. For these months, any of the operating strategies studied would produce cost savings.

\section{Conclusions}

This study considered the uncertainties in the cost savings associated with operating a CHP system under BL, FEL, and FTL operating strategies. This was achieved using a modular uncertainty analysis technique to compare the uncertainties associated with the cost savings of several evaluated operating strategies. Results indicated that, when uncertainties are taken into consideration, the selection of the most cost effective CHP operating strategy is not always clear. When considering uncertainty bands, the choice between operating strategies cannot always be readily determined. While trying to minimize yearly operating cost, given known hourly electrical and natural gas requirements, a clear selection between the CHP operating strategies considered cannot be made for PGU of sizes up to $60 \%$ of the building's maximum electrical 
load. While the uncertainty bands do overlap for some PGU sizes, the overlapping region is sometimes negligible. For example, at a PGU size of $60 \%$ of the building's maximum electrical load, the BL mode uncertainty band doesn't greatly overlap with the uncertainty band of the FEL strategy. At this PGU size, it is likely that the FEL strategy will have a better performance than that of the BL strategy. However, a judgment call would need to be made to determine the extent of overlap that would be deemed as acceptable. For PGU sizes larger than $60 \%$, the FEL and FTL operating strategies were determined to be a better choice than the BL operating strategy. However, it is still unclear as to whether a FEL or FTL operating strategy should be used with larger PGU sizes. It follows that the operating strategy which is easiest to implement and operate should be selected for any PGU size lower than $60 \%$ of the building's maximum electric load, and either the FEL or the FTL operating strategies should be chosen for PGU sizes larger than $60 \%$. At the optimal BL PGU size of 35\%, an unambiguous choice for a monthly CHP operating strategy cannot be made for all months. For the months of April through November, it was shown that any CHP operating strategy would be beneficial. In addition to those months, it was shown that FEL and FTL operating strategies would be beneficial for the months of February, and March. Thus, except for December and January, an FEL or FTL operating strategy should be chosen for any month of the year.

For the case when only monthly electrical and natural gas requirements are known, selection between different CHP operating strategies is even more difficult to determine. For the PGU sizes considered, a choice between the CHP operating strategies cannot be determined when trying to minimize yearly operating cost. In this case, the operating strategy which is easier to implement and operate should be selected. At the optimal BL PGU size of $80 \%$, the choice for a monthly CHP operating strategy cannot be made for all months. For the months of January through May and October through December, it was shown that any CHP operating strategy would be beneficial. The choice cannot be based solely upon cost reduction due to overlapping uncertainty bands. In regions of overlapping uncertainty bands, no definite choice of operating strategy can be determined and other considerations must be used to select an operating strategy. The work presented in this paper is a theoretical work detailing the uncertainty aspect of CHP operating strategies and experimental validation will be considered in future research.

\section{Acknowledgments}

Material presented in this paper is a product of the CREATE-GV Element of the 
Computational Research and Engineering Acquisition Tools and Environments (CREATE) Program sponsored by the U.S. Department of Defense HPC Modernization Program Office. This effort was sponsored under contract number W912HZ-13-C-0037.

\section{References}

[1] Amanda D. Smith, Pedro J. Mago, and Nelson Fumo. Benefits of thermal energy storage option combined with CHP system for different commercial building types. Sustainable Energy Technologies and Assessments, 1(0):3-12, 2013. ISSN 2213-1388.

[2] E. Jannelli, M. Minutillo, R. Cozzolino, and G. Falcucci. Thermodynamic performance assessment of a small size cchp (combined cooling heating and power) system with numerical models. Energy, 65(0): 240-249, 2014. ISSN 0360-5442.

[3] X.Q. Kong, R.Z. Wang, J.Y. Wu, X.H. Huang, Y. Huangfu, D.W. Wu, and Y.X. Xu. Experimental investigation of a micro-combined cooling, heating and power system driven by a gas engine. International Journal of Refrigeration, 28(7):977-987, 2005. ISSN 0140-7007. [4] Hui Li, Lin Fu, Kecheng Geng, and Yi Jiang. Energy utilization evaluation of cchp systems. Energy and Buildings, 38(3):253-257, 2006. ISSN 0378-7788.

[5] Anna Skorek-Osikowska, Åukasz Bartela, Janusz Kotowicz, Aleksander Sobolewski, Tomasz Iluk, and Leszek Remiorz. The influence of the size of the chp (combined heat and power) system integrated with a biomass fueled gas generator and piston engine on the thermodynamic and economic effectiveness of electricity and heat generation. Energy, 67(0):328-340, 2014. ISSN 0360-5442.

[6] Fangtian Sun, Lin Fu, Jian Sun, and Shigang Zhang. A new waste heat district heating system with combined heat and power (chp) based on ejector heat exchangers and absorption heat pumps. Energy, 69(0):516-524, 2014. ISSN 0360-5442. Energy and Environment: Bringing together Economics and Engineering.

[7] Francisco Toja-Silva and Antonio Rovira. A first and second thermodynamics law analysis of a hydrogen-fueled microgas turbine for combined heat and power generation. Journal of Engineering for Gas Turbines and Power, 136(2):021501-021501, October 2013. ISSN 0742-4795.

[8] Eva Thorin, Heike Brand, and Christoph Weber. Long-term optimization of cogeneration systems in a competitive market environment. Applied Energy, 81(2):152-169, 2005. ISSN 0306-2619. 
[9] Deepesh Sonar, S.L. Soni, and Dilip Sharma. Micro-trigeneration for energy sustainability: Technologies, tools and trends. Applied Thermal Engineering, 71(2):790-796, 2014. ISSN 1359-4311. Special Issue: MICROGEN III: Promoting the transition to high efficiency distributed energy systems.

[10] Manijeh Alipour, Kazem Zare, and Behnam Mohammadi-Ivatloo. Short-term scheduling of combined heat and power generation units in the presence of demand response programs. Energy, 71(0):289-301, 2014. ISSN 0360-5442.

[11] E. Cardona and A. Piacentino. A validation methodology for a combined heating cooling and power (CHCP) pilot plant. Journal of Energy Resources Technology, 126(4):285-292, December 2004. ISSN 0195-0738.

[12] Nelson Fumo, Pedro J. Mago, and Louay M. Chamra. Energy and economic evaluation of cooling, heating, and power systems based on primary energy. Applied Thermal Engineering, 29(13):2665-2671, 2009. ISSN 1359-4311.

[13] Nelson Fumo, Pedro J. Mago, and Louay M. Chamra. Analysis of cooling, heating, and power systems based on site energy consumption. Applied Energy, 86(6):928-932, 2009. ISSN 0306-2619.

[14] Ali A. Jalalzadeh-Azar. A comparison of electrical- and thermal-load-following CHP systems. ASHRAE Transactions, 110(2):85-94, 2004. ISSN 00012505.

[15] Jun Young Kang, Do Won Kang, Tong Seop Kim, and Kwang Beom Hur. Comparative economic analysis of gas turbine-based power generation and combined heat and power systems using biogas fuel. Energy, 67(0):309-318, 2014. ISSN 0360-5442.

[16] Alta A. Knizley, Pedro J. Mago, and Amanda D. Smith. Evaluation of the performance of combined cooling, heating, and power systems with dual power generation units. Energy Policy, 66(0):654-665, 2014. ISSN 0301-4215.

[17] P.J. Mago, N. Fumo, and L.M. Chamra. Performance analysis of CCHP and CHP systems operating following the thermal and electric load. International Journal of Energy Research, 33(9):852-864, 2009. cited By (since 1996)85.

[18] Pedro J. Mago, Anna Hueffed, and Louay M. Chamra. Analysis and optimization of the use of CHP-ORC systems for small commercial buildings. Energy and Buildings, 42(9):1491-1498, 2010. ISSN 0378-7788.

[19] Pedro J. Mago, Rogelio Luck, and Alta Knizley. Combined heat and power systems with 
dual power generation units and thermal storage. International Journal of Energy Research, 38(7):896-907, 2014. ISSN 1099-114X.

[20] Amanda D. Smith and Pedro J. Mago. Effects of load-following operational methods on combined heat and power system efficiency. Applied Energy, 115(0):337-351, 2014. ISSN 0306-2619.

[21] Z.G. Sun, R.Z. Wang, and W.Z. Sun. Energetic efficiency of a gas-engine-driven cooling and heating system. Applied Thermal Engineering, 24(56):941-947, 2004. ISSN 1359-4311. [22] Jiang-Jiang Wang, You-Yin Jing, Chun-Fa Zhang, and Zhiqiang (John) Zhai. Performance comparison of combined cooling heating and power system in different operation modes. Applied Energy, 88(12): 4621-4631, 2011. ISSN 0306-2619.

[23] D.W. Wu and R.Z. Wang. Combined cooling, heating and power: A review. Progress in Energy and Combustion Science, 32(56):459-495, 2006. ISSN 0360-1285.

[24] Heejin Cho, Pedro J. Mago, Rogelio Luck, and Louay M. Chamra. Evaluation of CCHP systems performance based on operational cost, primary energy consumption, and carbon dioxide emission by utilizing an optimal operation scheme. Applied Energy, 86(12):2540-2549, 2009. ISSN 0306-2619.

[25] Kyung Tae Yun, Heejin Cho, Rogelio Luck, and Pedro J. Mago. Modeling of reciprocating internal combustion engines for power generation and heat recovery. Applied Energy, 102(0):327-335, 2013. ISSN 0306-2619. Special Issue on Advances in sustainable biofuel production and use - XIX International Symposium on Alcohol Fuels - ISAF. [26] Heejin Cho. Dynamic simulation and optimal real-time operation of CHP systems for buildings. Mississippi State: Mississippi State University, 2009, 2009.

[27] J.B. Weathers, R. Luck, and J.W. Weathers. A modular approach to linear uncertainty analysis. ISA Transactions, 49(1):19-26, 2010. ISSN 0019-0578.

[28] M.A.S. Jeronimo, L.F. Melo, A. Sousa Braga, P.J.B.F. Ferreira, and C. Martins. Monitoring the thermal efficiency of fouled heat exchangers: A simplified method. Experimental Thermal and Fluid Science, 14(4):455-463, 1997. ISSN 0894-1777. Heat Exchange Fouling.

[29] US Bureau of Labor Statistics. http://data.bls.gov/cgi-bin/surveymost?ap.

[30] US DOE Commerical Reference Buildings. http://energy.gov/eere/buildings/commercial-reference-buildings.

\section{List of Tables}


Table 1. Chicago Restaurant Description

Table 2. External Inputs

Table 3. System Components

\section{List of Figures}

Figure 1. Schematic of CHP system

Figure 2. Block diagram used for the CHP operating strategy

Figure 3. Block diagram of conventional heating system

Figure 4. Block diagram of CHP system operating in BL strategy

Figure 5. Block diagram of CHP system operating in FEL strategy

Figure 6. Block diagram of combined heat and power (CHP) system operating in FTL strategy

Figure 7. Yearly operating cost reduction versus PGU size for BL, FEL, and FTL operating strategy

Figure 8. Monthly operating cost of CHP system at optimal BL PGU size (35\% of building's max electrical load)

Figure 9. Yearly operating cost reduction versus PGU size for BL, FEL, and FTL operating strategy based upon monthly inputs

Figure 10. Monthly operating cost of CHP system at optimal BL PGU size (80\% of building's max electrical load) based upon monthly inputs

Table 1. Chicago Restaurant Description [30]

\begin{tabular}{|l|l|}
\hline Building Type Name & Full Service Restaurant \\
\hline Floor Area $\left(m^{2}\right)$ & 511 \\
\hline $\begin{array}{l}\text { Total Electricity } \\
(\mathrm{kWh} / \mathrm{yr})\end{array}$ & 314,713 \\
\hline $\begin{array}{l}\text { Total Fuel Energy } \\
(\mathrm{kWh} / \mathrm{yr})\end{array}$ & 544,085 \\
\hline Number of Floors & 1 \\
\hline Climate Zone & $5 \mathrm{~A}$ \\
\hline Location & Chicago, Illinois \\
\hline
\end{tabular}

Table 2. External Input parameters in CHP system 


\begin{tabular}{|l|l|l|l|l|}
\hline Variable & Symbol & Value & Random Uncertainty & Systematic Uncertainty \\
\hline $\begin{array}{l}\text { Boiler } \\
\text { Efficiency }\end{array}$ & $\eta_{\text {boiler }}$ & 0.8 & $0.04(5 \%)$ & $0.04(5 \%)$ \\
\hline $\begin{array}{l}\text { Heating Coil } \\
\text { Efficiency }\end{array}$ & $\eta_{h c}$ & 0.8 & $0.04(5 \%)$ & $0.04(5 \%)$ \\
\hline $\begin{array}{l}\text { PGU Heat } \\
\text { Recovery } \\
\text { Efficiency }\end{array}$ & $\eta_{\text {rec }}$ & 0.8 & $0.04(5 \%)$ & $0.04(5 \%)$ \\
\hline $\begin{array}{l}\text { Electric Cost } \\
\text { \$/kWh) }\end{array}$ & $C_{e}$ & $0.077[29]$ & 0 & $0.00285(3.7 \%)$ \\
\hline $\begin{array}{l}\text { Natural Gas } \\
\text { Cost } \\
\text { (\$/kWh) }\end{array}$ & $C_{f}$ & $0.03[29]$ & 0 & $0.00087(2.9 \%)$ \\
\hline $\begin{array}{l}\text { First PGU } \\
\text { relationship } \\
\text { constant }\end{array}$ & $a$ & 2.3698 & 0 & $0.0550(2.32 \%)$ \\
\hline $\begin{array}{l}\text { Second PGU } \\
\text { relationship } \\
\text { constant }\end{array}$ & $b$ & 1.0322 & 0 & $0.0504(4.88 \%)$ \\
\hline
\end{tabular}

Table 3. CHP System Components

\begin{tabular}{|l|l|l|l|l|}
\hline Symbol & Conventional & BL & FEL & FTL \\
\hline$\eta_{\max }$ & & $\checkmark$ & & $\checkmark$ \\
\hline$\eta_{p g u}$ & & & $\checkmark$ & \\
\hline Cost $_{B L}$ & & $\checkmark$ & & \\
\hline Cost $_{\text {conv }}$ & $\checkmark$ & $\checkmark$ & $\checkmark$ & $\checkmark$ \\
\hline Cost $_{\text {conv-BL }}$ & & $\checkmark$ & & \\
\hline Cost $_{\text {conv } F E L}$ & & & & $\checkmark$ \\
\hline Cost $_{\text {conv-FTL }}$ & & & $\checkmark$ & \\
\hline
\end{tabular}




\begin{tabular}{|c|c|c|c|c|}
\hline $\operatorname{Cost}_{F E L}$ & & & & $\checkmark$ \\
\hline $\operatorname{Cost}_{F T L}$ & & $\checkmark$ & $\checkmark$ & $\checkmark$ \\
\hline$E_{\text {grid }}$ & & & $\checkmark$ & $\checkmark$ \\
\hline$E_{p g u}$ & & & $\checkmark$ & $\checkmark$ \\
\hline$E_{\text {nom }}$ & & $\checkmark$ & $\checkmark$ & $\checkmark$ \\
\hline$\overline{F_{b}}$ & $\checkmark$ & $\checkmark$ & $\checkmark$ & $\checkmark$ \\
\hline$F_{\text {boiler }}$ & & $\checkmark$ & & $\checkmark$ \\
\hline$F_{m}$ & & $\checkmark$ & $\checkmark$ & $\checkmark$ \\
\hline$F_{\max }$ & & $\checkmark$ & & $\checkmark$ \\
\hline$F_{p g u}$ & & & $\checkmark$ & $\checkmark$ \\
\hline $\operatorname{Mon}_{B L}$ & & $\checkmark$ & & \\
\hline $\operatorname{Mon}_{\text {conv }}$ & $\checkmark$ & $\checkmark$ & $\checkmark$ & $\checkmark$ \\
\hline$M_{\text {conv }-B L}$ & & $\checkmark$ & & \\
\hline Mon $_{\text {conv }-F E L}$ & & & $\checkmark$ & \\
\hline$M_{\text {on }}{ }_{\text {conv }-F T L}$ & & & & $\checkmark$ \\
\hline Mon $_{F E L}$ & & & $\checkmark$ & \\
\hline Mon $_{F T L}$ & & & & $\checkmark$ \\
\hline$Q_{\text {boiler }}$ & & $\checkmark$ & $\checkmark$ & $\checkmark$ \\
\hline$Q_{h c}$ & & $\checkmark$ & $\checkmark$ & $\checkmark$ \\
\hline$Q_{\max }$ & & $\checkmark$ & & $\checkmark$ \\
\hline$Q_{r}$ & & & $\checkmark$ & $\checkmark$ \\
\hline Year $_{B L}$ & & $\checkmark$ & & \\
\hline Year $_{\text {conv }}$ & $\checkmark$ & $\checkmark$ & $\checkmark$ & $\checkmark$ \\
\hline Year $_{\text {conv }-B L}$ & & $\checkmark$ & & \\
\hline Year $_{\text {conv }-F E L}$ & & & $\checkmark$ & \\
\hline
\end{tabular}




\begin{tabular}{|l|l|l|l|l|}
\hline Year $_{\text {conv FTL }}$ & & & & $\checkmark$ \\
\hline Year $_{F E L}$ & & & $\checkmark$ & \\
\hline Year $_{F T L}$ & & & & $\checkmark$ \\
\hline
\end{tabular}


Figure 1. Schematic of combined heat and power (CHP) system

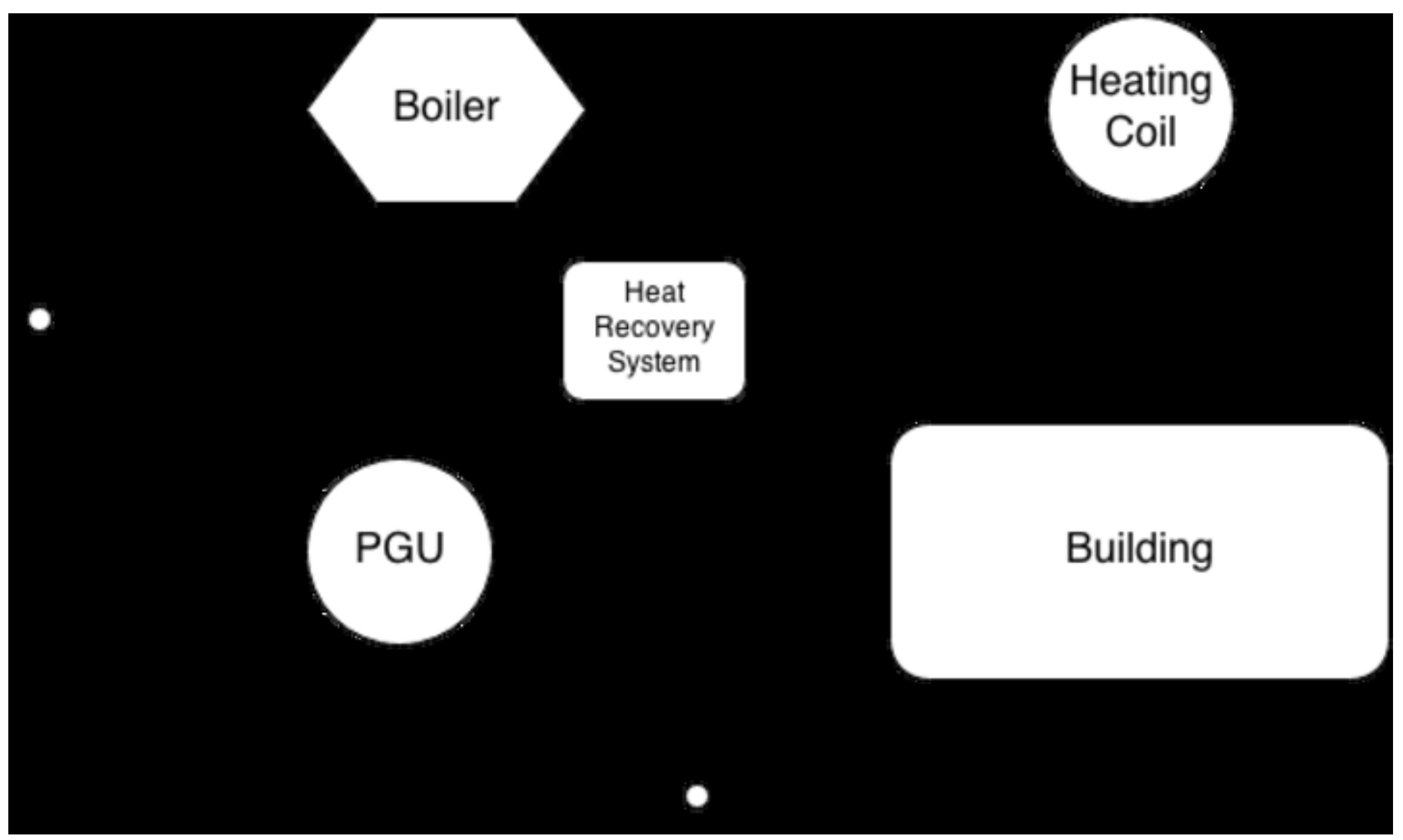

Heat

Recovery

System

\section{Building}

PGU

$\bullet$

Heating Coil

更

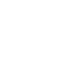

更
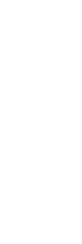
Figure 2. Block diagram used for the CHP operating strategy

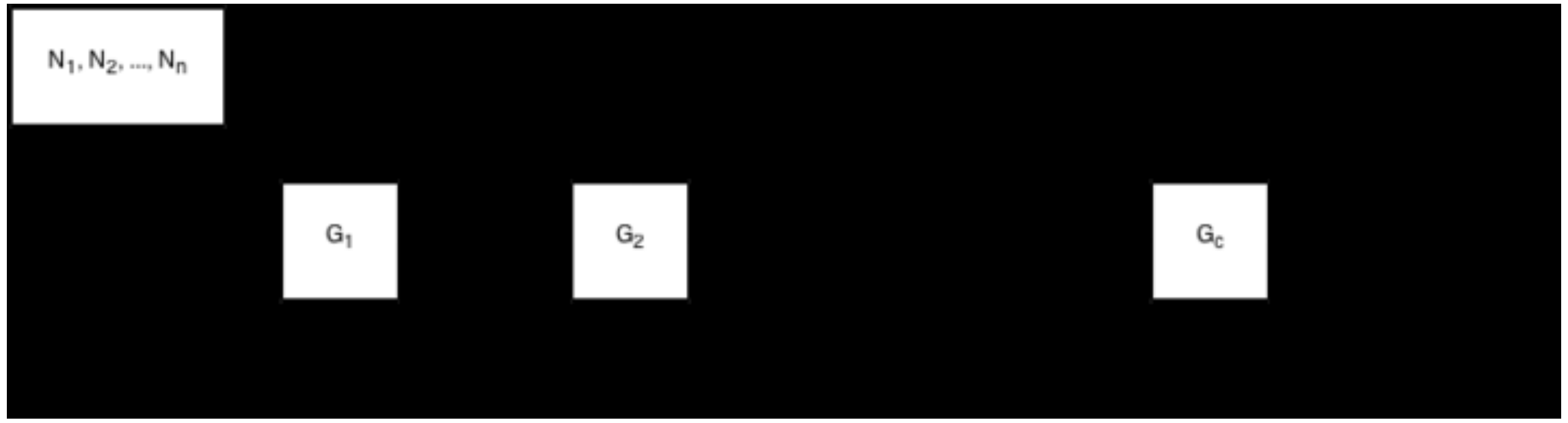


Figure 3. Block diagram of conventional heating system

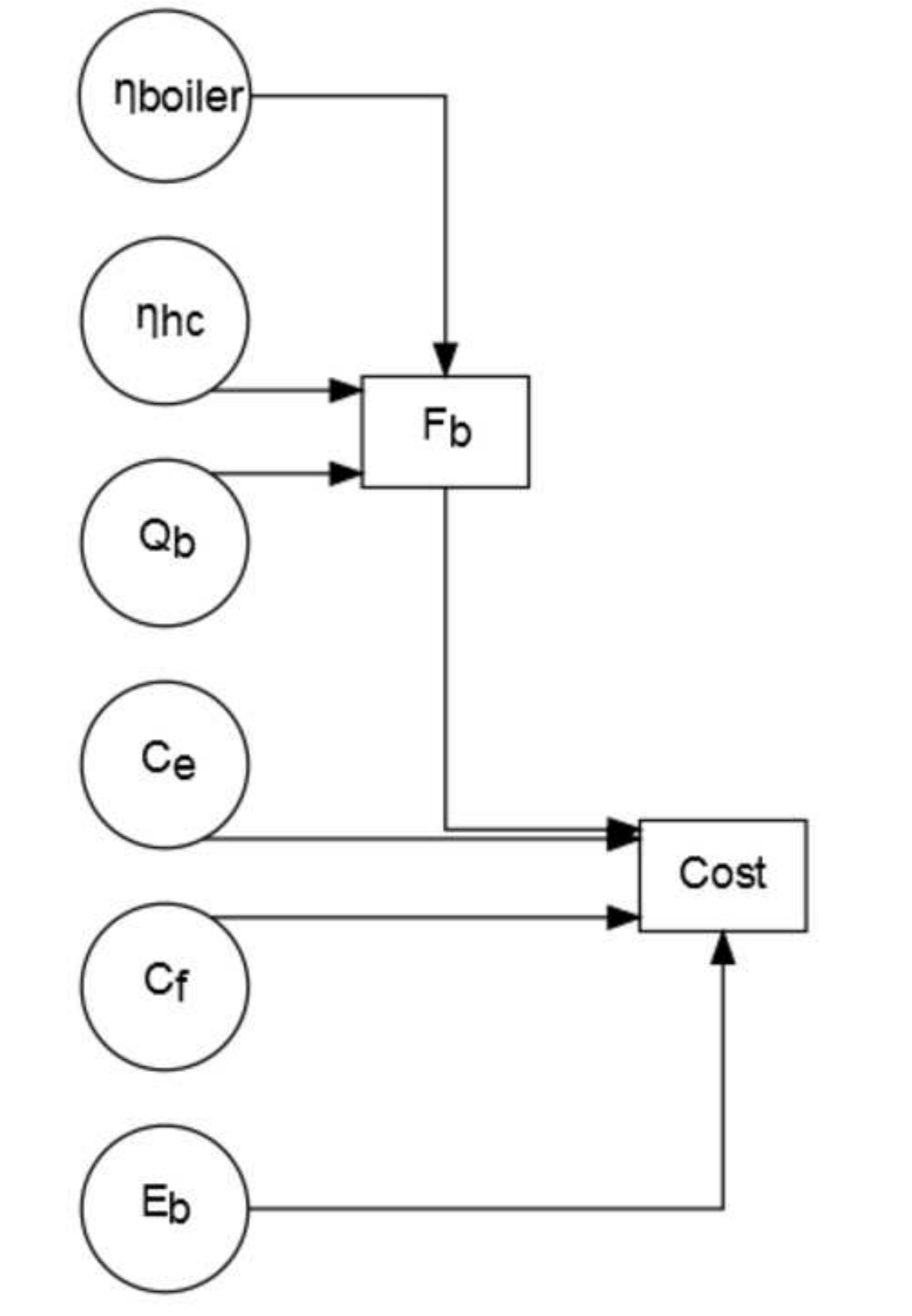

.
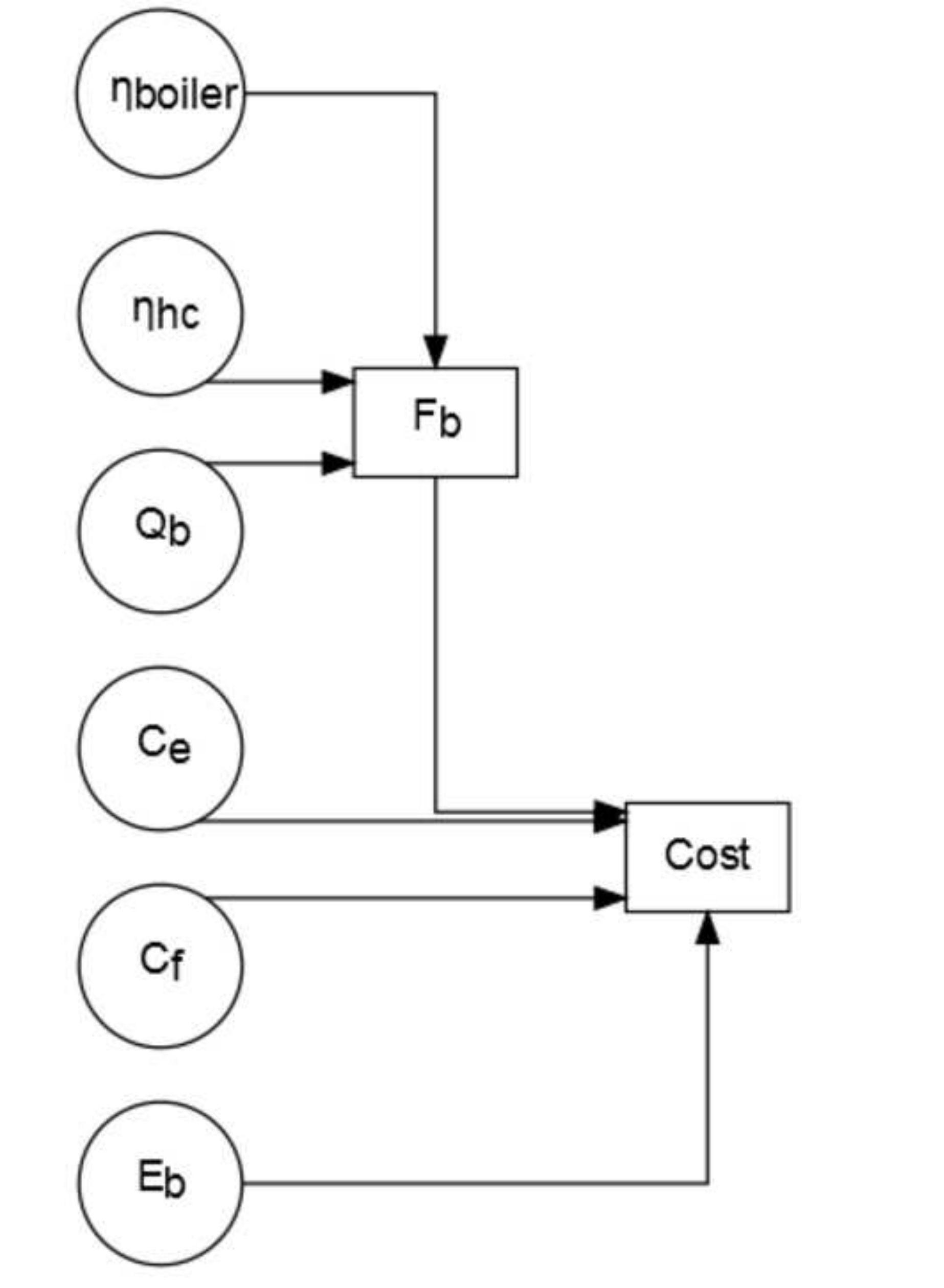
Figure 4. Block diagram of combined heat and power (CHP) system

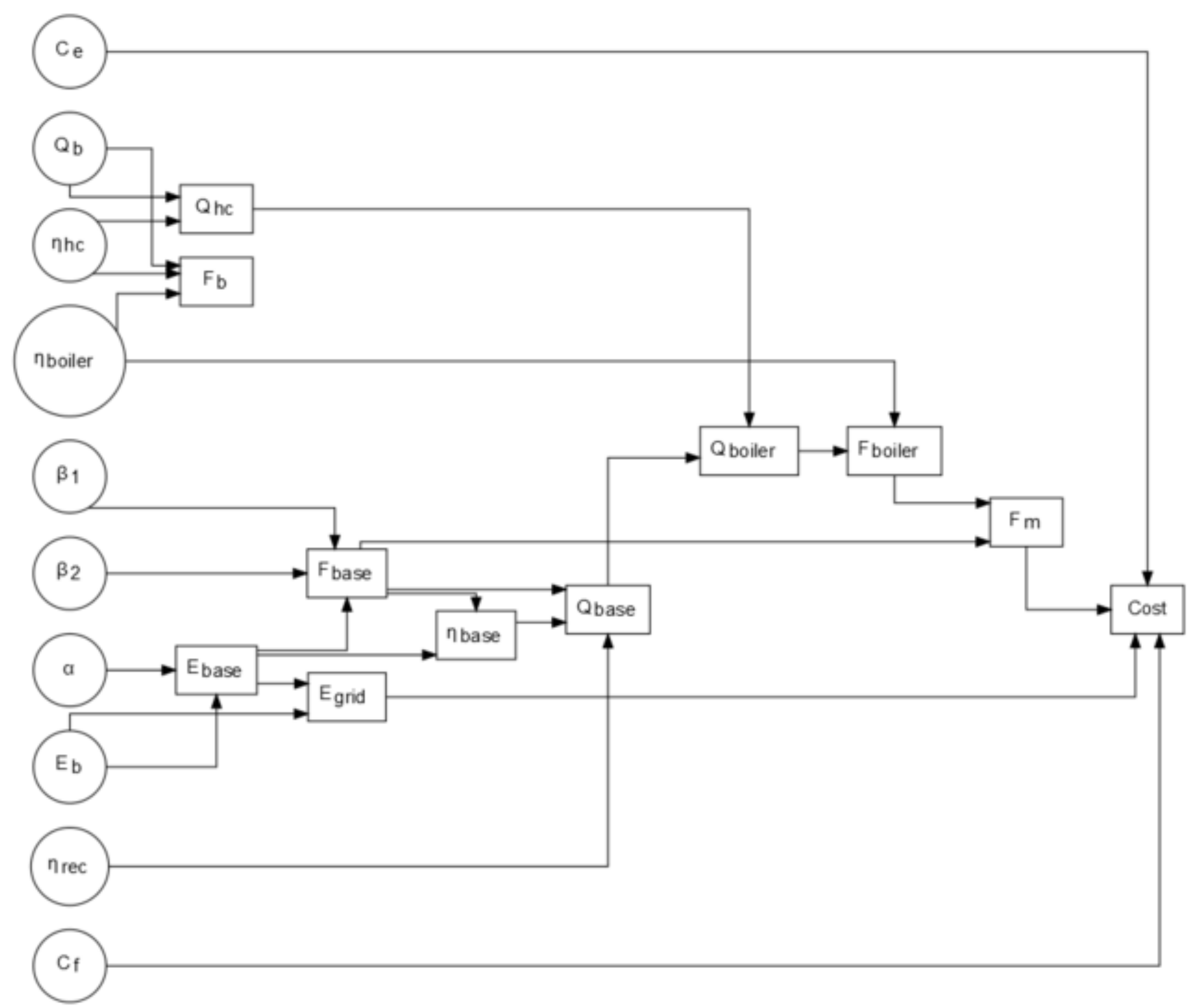


Figure 5. Block diagram of combined heat and power (CHP) system

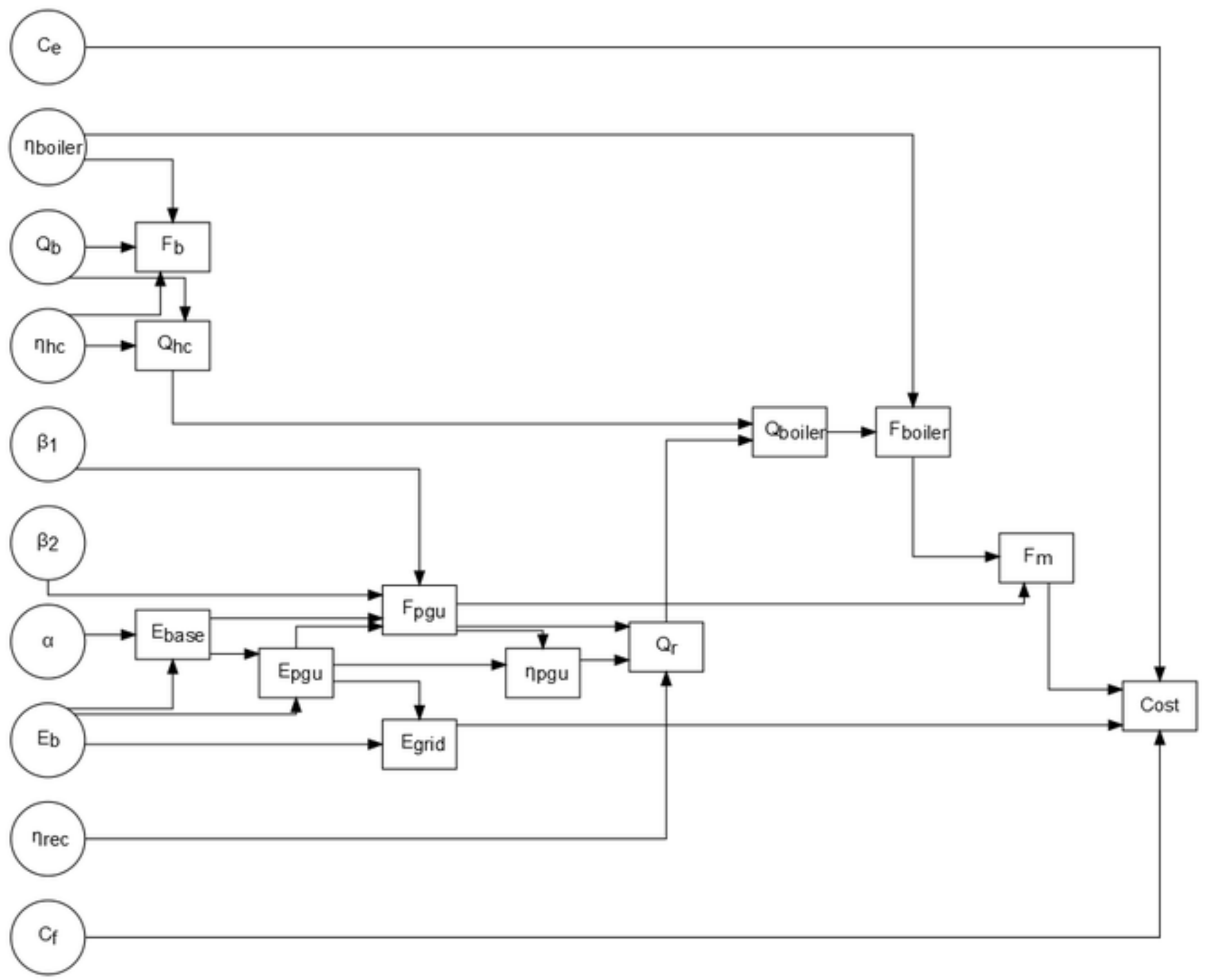


Figure 6. Block diagram of combined heat and power (CHP) system

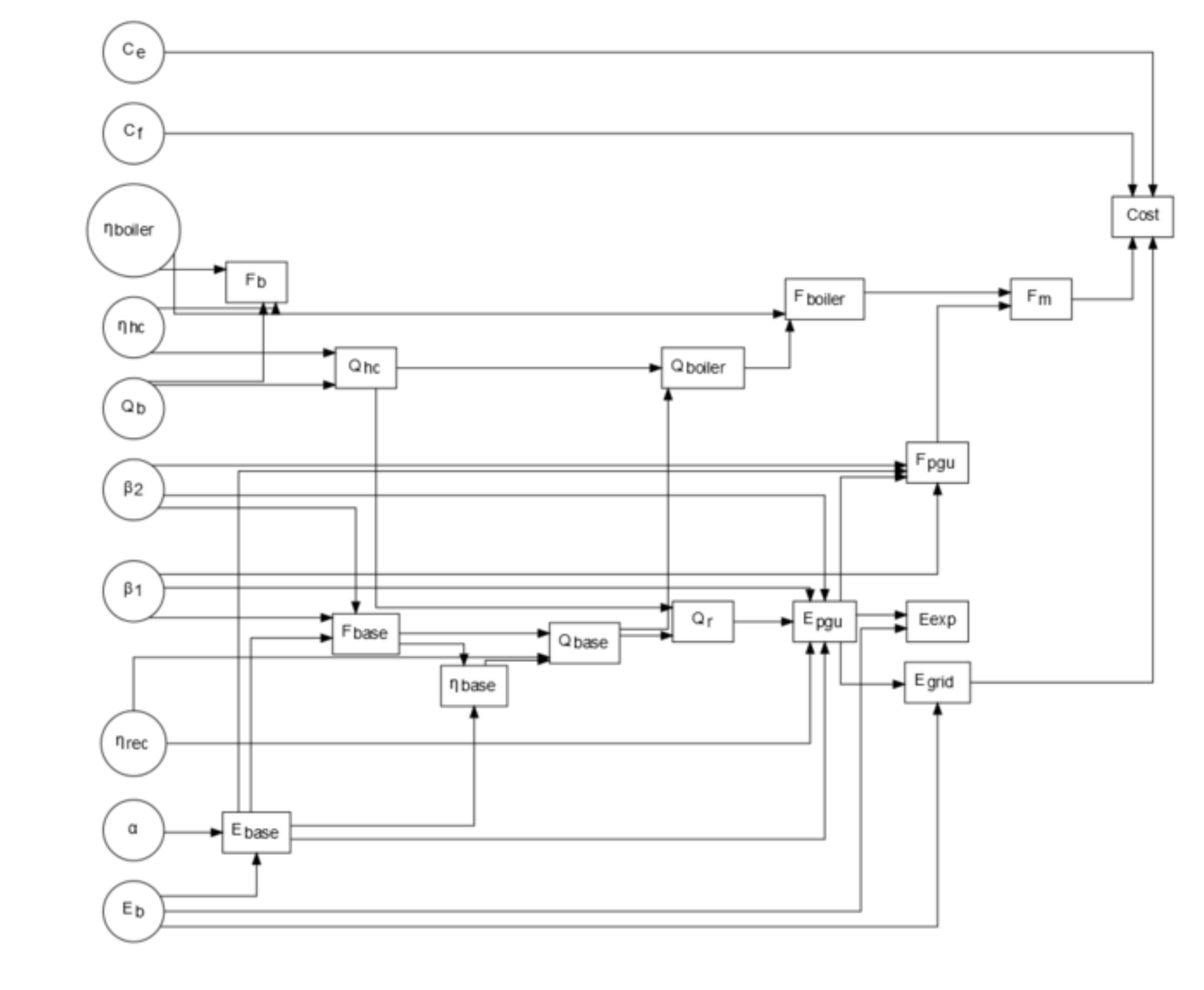

列

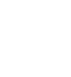




\section{Yearly Operating Cost Reduction vs PGU size}

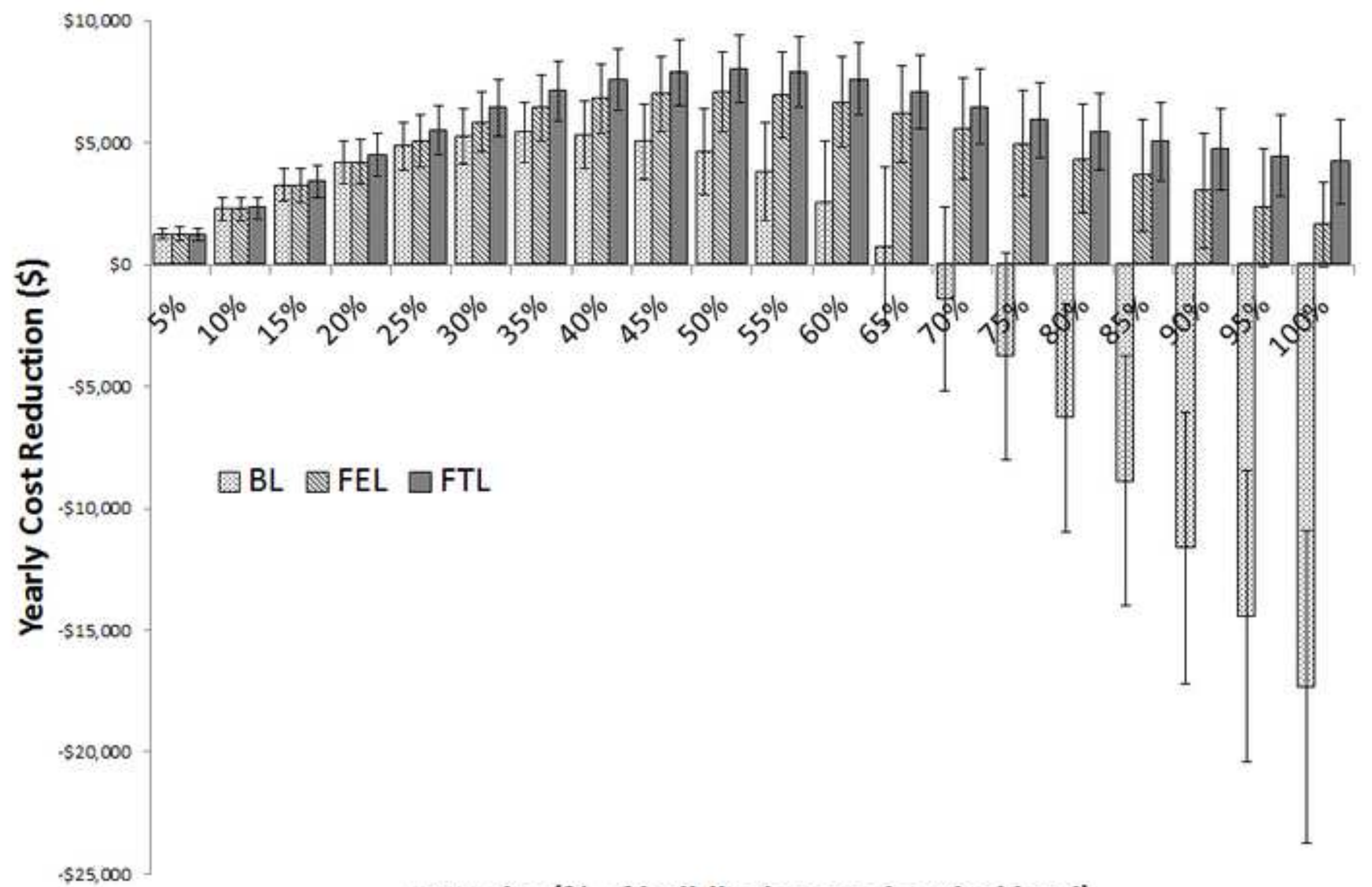

PGU size (\% of building's max electrical load) 


\section{Monthly Operating Cost at optimal BL PGU size}

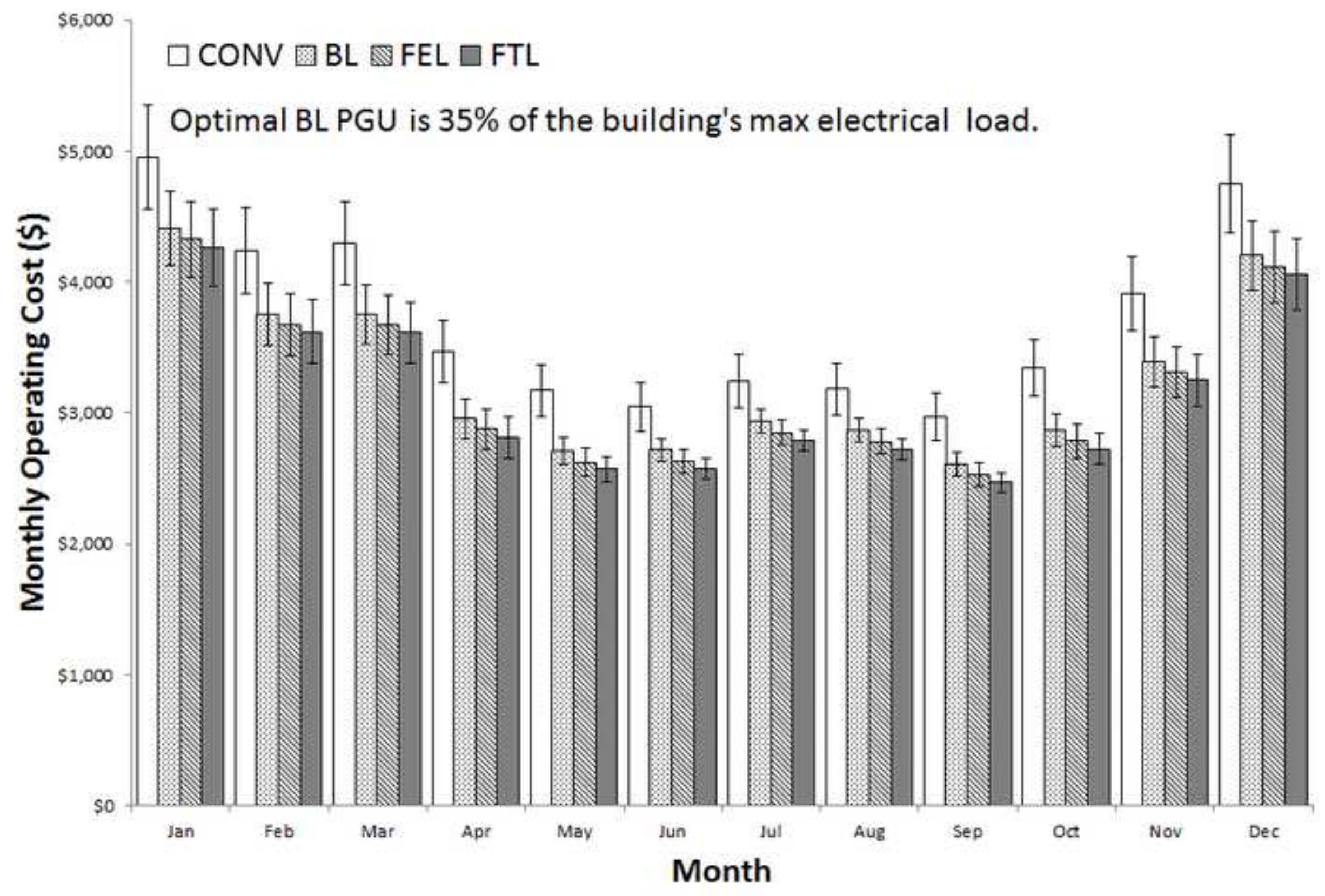




\section{Yearly Operating Cost Reduction vs PGU size based upon monthly inputs}

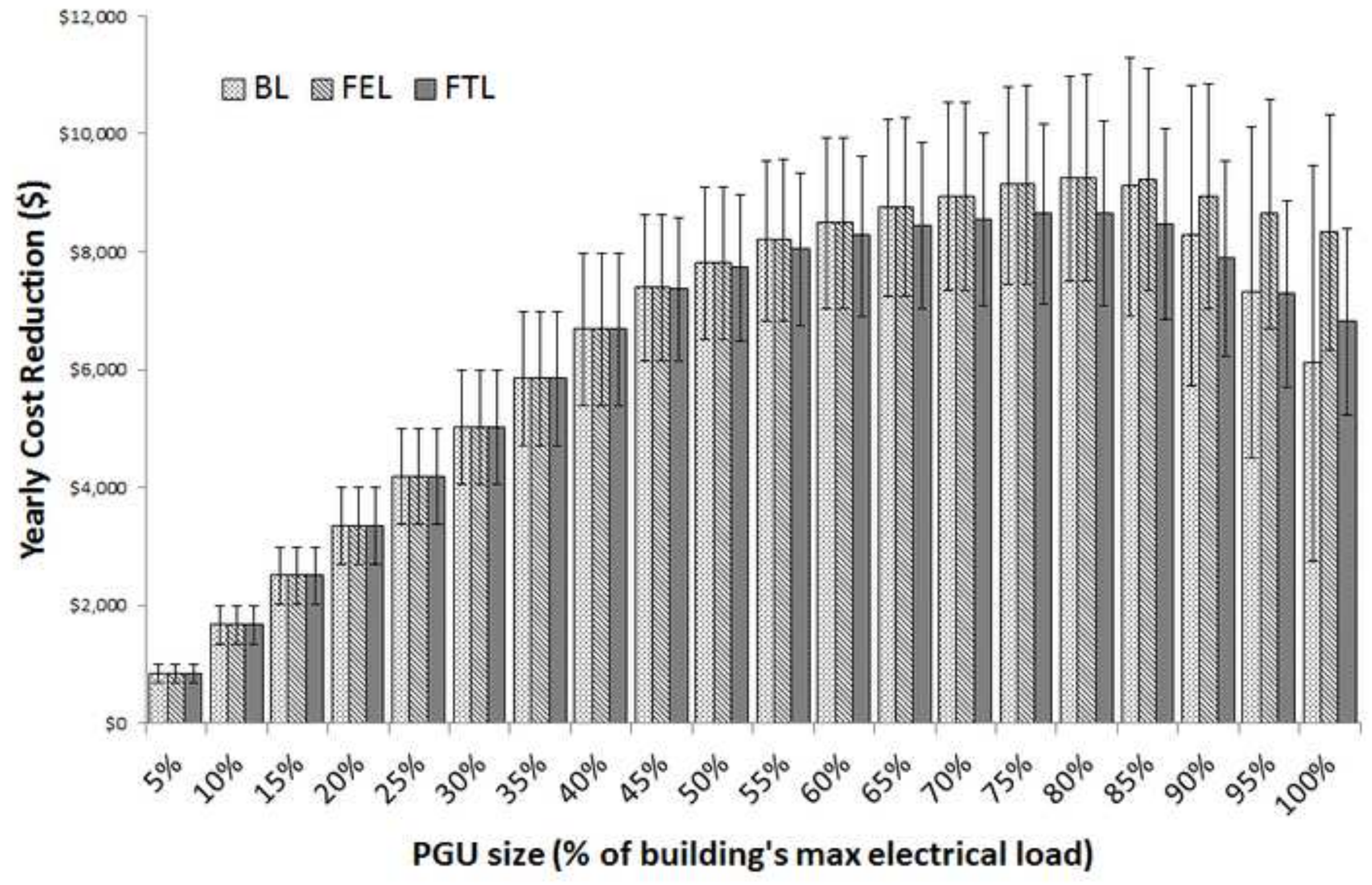




\section{Monthly Operating Cost at optimal BL PGU size based upon monthly inputs}

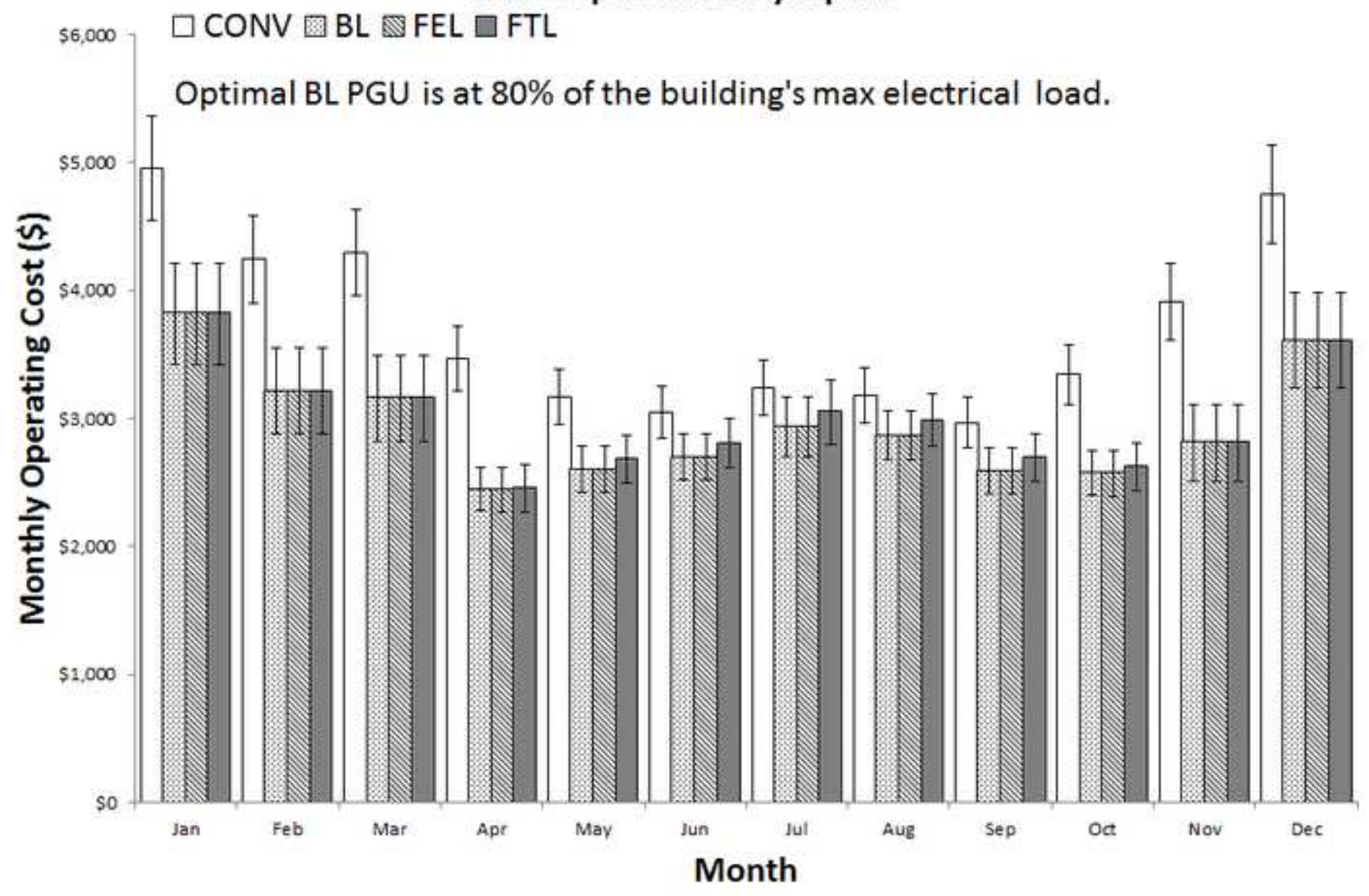

